\title{
Proposal for a Battery Model for Evaluation Functional Beach Volleyball Athlete
}

\author{
Julio Cesar de Faria Pastore ${ }^{1,2,3}$, Paulo Vicente Joao ${ }^{3}$ \\ ${ }^{1}$ Physical Education, Estácio de Sá University - Rio de Janeiro - Brazil \\ ${ }^{2}$ Laboratory of Physiology of Exercise \& Measurements and Evaluation (LAFIEX), Estácio de Sá \\ University - Rio de Janeiro \\ ${ }^{3}$ Research Center in Sports Science, Health and Human Development (CIDESD), University of Trás- \\ os-Montes and Alto Douro - Vila Real - Portugal
}

\begin{abstract}
This study aimed to develop a battery of pilot tests for functional assessment of the Beach Volleyball athlete, following the norm of the Brazilian Association of Technical Standards (ABNT, MB-1059/86). The sample consisted of eighteen $(n=18)$ female athletes of Brazilian nationality, with a mean age of $24 \pm 4.35$ years and height of $1.76 \pm 0.05 \mathrm{~cm}$, federate with one year of competitions in circuit Bank of Brazil and the World tour. They evaluated three physical abilities in two different places (the beach of Ipanema and Barra Rio de Janeiro). The analyzed capacities were agility, speed, launched speed and power, where no significant differences. However, it was possible to create a possible profile of the female athlete in the Brazilian beach volleyball.
\end{abstract}

Keywords: Battery testing, Functional profile, Beach Volleyball.

\section{INTRODUCTION}

There are several tests and batteries that measure different components of physical fitness, and an important tool in the evaluation within the sport, making it essential in the quest for specificity of each sport. According to Pitanga ${ }^{1}$ in their understanding, battery testing, is a set of well-defined tests, reliable and valid for a given population, by which is intended to evaluate certain parameters.

Volleyball in this context was the modality that most changed their rules in recent years in search of a better income. In Brazil the sport has evolved in a big way, becoming a school in the world sports scene, where Brazilian teams have achieved great prominence in all categories and today is record of international titles (Gilmário²).

From this point of view, the work execution capabilities to enhance the performance of player during a match are from the anaerobic metabolism, with higher energy contributions phosphagenic system, which availability will be needed this system in muscle maintenance and support work close to their maximum (anaerobic performance), increasing the resynthesis of phosphocreatine during periods of recovery through the aerobic system contribution (Barbanti ${ }^{3}$; Tubino \& Moreira ${ }^{4}$; Arruda \& Hespanhol $^{5}$ ).

The fast power capacity is described as the highest exponent force that the neuromuscular system is capable of producing, regardless of the time factor, which helps greatly in vertical jumps (Carvalho \& Carvalho ${ }^{6}$.

Because it is a sport that requires high-speed offset by the athletes, agility exercises great importance, because it allows changes of direction without loss of speed and rhythm. According to previous studies Kraemer \& Hakkinem ${ }^{7}$; Ré et al. ${ }^{8}$, agility is an innate ability that is related to the requirement of sport practiced, therefore, should be developed along the entire sporting life with training. Taking into considering these physical abilities required for the sport, the present study aims to investigate the influence of the characteristics of physical agility valences, speed and power through a test battery, and thus establish parameters for evaluating these valences.

Considering the possible outcomes, it is essential to investigate the behavior athletic performance in physical tests in beach volleyball, and at the same time, adopt possible battery models for functional evaluation of beach volleyball athletes. 


\section{METHODS}

Participated in this study $\mathrm{n}=18$ athletes female of beach volleyball, within the age range between 20 and 32 years $(24 \pm 4.35$ years $)$ and height $(1.76 \pm 0.05 \mathrm{~cm})$, which training on the beaches of the south zone of Rio de Janeiro, federated participants from Bank of Brazil Circuit of Beach Volleyball and Beach Volleyball World Tour, at least one year. They evaluated three physical abilities in two different beaches (Ipanema and Barra - Rio de Janeiro). The analyzed capacities were agility, speed, launched speed and power, where no significant differences.

\subsection{Test Procedures}

The tests were performed in the morning between 8:00 and 10:00 am, given that most training occurs in the same time.

Following the aim of studying the effect of the characteristics of the physical parameters, the tests were performed on two occasions in two beach volleyball courts located in different beaches of Rio de Janeiro.

Before the test day, all participants were instructed not to do strenuous physical activity in the previous 24 hours, do not drink caffeinated or alcoholic drinks in the three hours before the tests, and wear light clothing in the ratings and sleeping 6 to 8 hours on the day of tests. Between each assessment remained a minimum of 48 to 72 hours.

The first day of evaluation, evaluated underwent an anamnesis, including information on risk factors, history of injuries and surgeries, sequentially held the anthropometric measurements, height and body mass.

On the second day, there was a battery of tests assessing agility, power and speed. Finally, the third day, there was the same test battery evaluating agility, power and speed, and in a distinguished court from the second day.

In the collection of anthropometric data was adopted the standard established by the International Society for Advances of Kinathropometry (ISAK ${ }^{9}$ ) in order to record the height, body mass, skinfold thickness and body circumferences. Anthropometric evaluation was used the mathematical model for the body density of women developed by Jackson \& Pollock ${ }^{10}$, the equation of Siri (1961), the percentage of body fat and body mass index (BMI) developed by Quetelet (1841). However the check body mass was used a scale Tanita MC-780MAP (Tanita®, Japan) (Multi Frequency Segmental Body Composition Analyser with Interative Console) and height a portable stadiometer (Sanny®, Brazil) with precision $0,01 \mathrm{~kg}$ and $0.001 \mathrm{M}$.

In measuring the skinfolds the same measure was used in all measures (Lange ${ }^{\circ}$, USA) with precision $0,01 \mathrm{~cm}$. Finally as the perimeters used a metal tape measure anthropometric (Sanny®, Brazil) with precision $0,01 \mathrm{~cm}$.

To measure and record the agility of the times, power and speed we used a speed meter photocell EQ34 Sunx® model and Multisprint software.

\subsection{Physical Tests}

All physical tests were performed three times, keeping every two minutes of rest between them not being allowed to stretch, sit or lie down. Finally, we computed the shortest time among the three trials.

Two distinct courts of beach volleyball were used. To demarcate the area using four blue color ribbons with $8.00 \times 0.05 \mathrm{~m}$ each. In the protocol to evaluate the agility we used the half court sizes with a $64 \mathrm{~m}^{2}$ area, whose boundaries were determined by a frontal ribbon, background ribbon, ribbon right and left. To speed assessment protocol, we used the total length of the block with 16x8 $\mathrm{m}$ long.

\subsection{Protocol for Assessing Agility}

Each evaluated positioned himself standing with both feet behind the front ribbon on the right side (point "a") of the volleyball court in the "start" (Figure 1), which was positioned only photocell. The test started and finished so that some part of the athlete's body to interrupt the light barrier photocell. The assessed was encouraged to perform the route of the race in the shortest time possible following the path shown in Figure 1 (dashed line); it was computed the time between the start and the finish. 


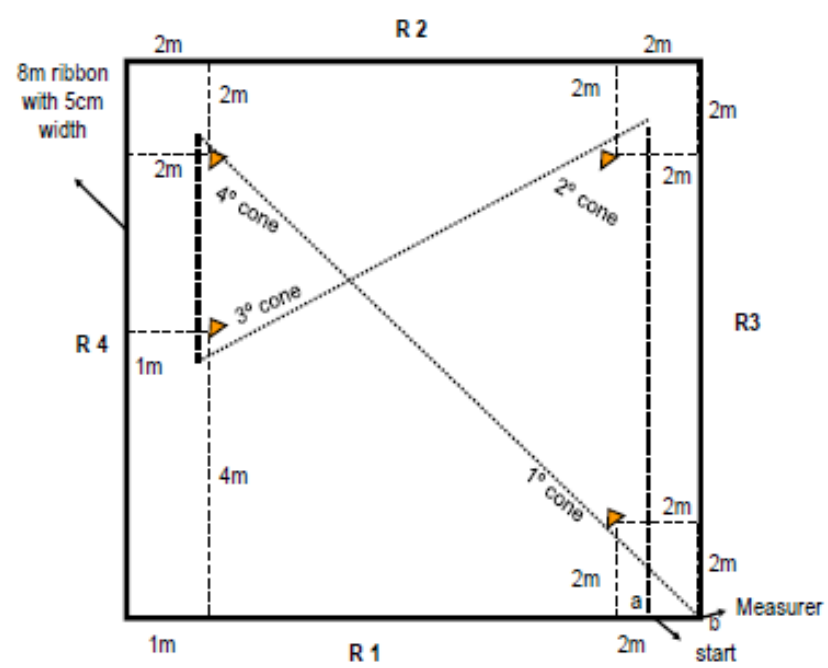

Figure1. Scheme route marked out to evaluate the agility ability in beach volleyball. The solid line is the ribbons that demarcate size of the block (R1, R2, R3 and R4), the dotted demarcate the route to be followed and broken, are marking the position of the four cones.

\subsection{Protocol for Assessing Speed}

For the speed test, each evaluated remained in a standing position with both feet behind the front ribbon on the left side of the volleyball court in the "start" (Figure 2). The photocells were positioned so that the left first ribbon vertex, with the frontal ribbon at the starting line and second positioned at the left corner ribbon with the ribbon background. The test started as soon as any part of the athlete's body to interrupt the light barrier of the first photocell; therefore, the athlete did not expect the evaluator's sign, which had the only function to release the test track.

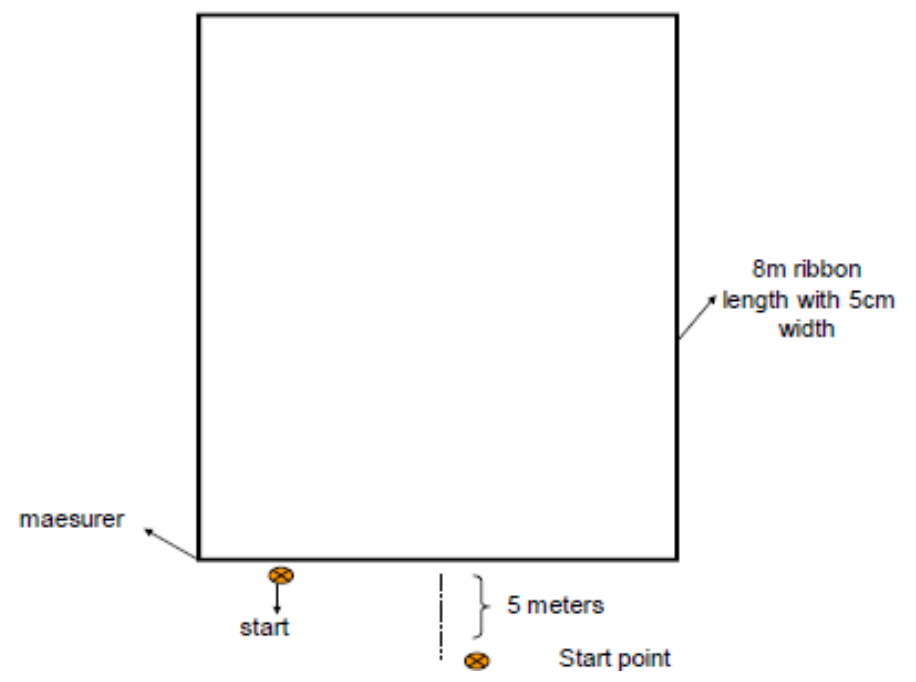

Figure2. Scheme of the route marked out to assess the speed capabilities and speed released in beach volleyball. The solid line are the ribbons that mark the size of the court, the points orange forward the ribbon, are the cone that mark the positions of starts speed test and speed released.

\subsection{Protocol for Assessing Launched Speed}

Assessment of launched speed followed protocol similar to the above, but were given 5 meters accelerating point "start" (Figure 2).

\subsection{Protocol for Assessing of Power}

Each athlete was evaluated in the standing position with both feet behind the limiting range of $1.00 \mathrm{x}$ $0.05 \mathrm{~m}$ that was parallel to and $20 \mathrm{~cm}$ from the first barrier (Figure 3). The testing began Jump one on the 1st and 2nd barrier (round trip) following the sequence of four jumps and all of the passages on the same were with the body facing the same with knees in a "grouped" and feet touched the soil simultaneously without there being gaps between them. The barriers made of half inch PVC 
(Polyvinyl chloride) pipe of which lateral rods with $60 \mathrm{~cm}$ high and $80 \mathrm{~cm}$ upper shaft. The same were spaced and positioned parallel to $1 \mathrm{~m}$ between them. Each barrier was with his upper stem $40 \mathrm{~cm}$ above the ground.

The test started as soon as any part of the athlete's body to interrupt the light barrier single photocell positioned in boundary line, so the athlete did not expect the measurer signal.

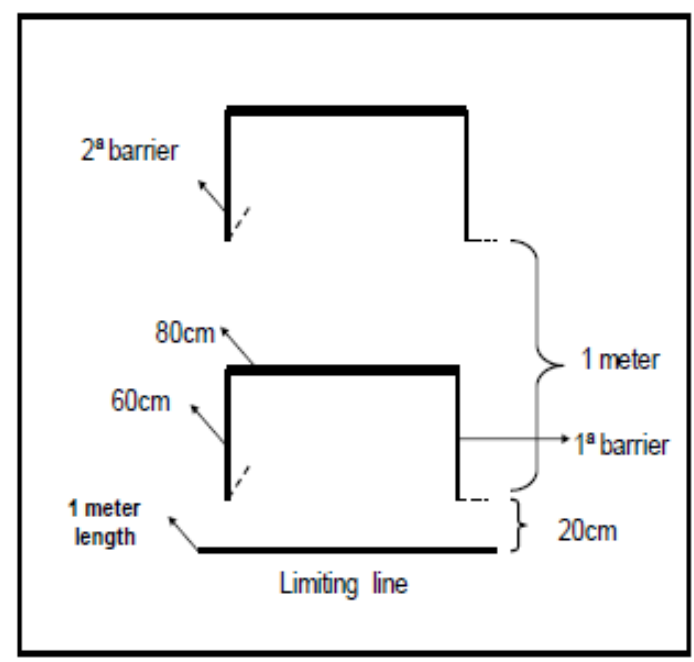

Figure3. Test scheme to assess the power capacity in beach volleyball. The solid lines are the ribbons that mark the size of the court. The limiting line and the location from which depart evaluated. The barriers are made of $P V C$ with its upper stem $80 \mathrm{~cm}$ and $60 \mathrm{~cm}$ lateral rods.

\section{Statistical}

For analysis and processing of data, this study used descriptive statistics with measures of central tendency and dispersion (mean, median, standard deviation and variance) and sample normal check through the Shapiro-Wilk test. As inferential analysis, we used asymmetry and kurtosis calculations to verify the distribution of the data.

In order to appreciation of test results between the beaches was realized Test "T" Student. The confidence level for data analysis was $\mathrm{p}<0.05$. Data were analyzed using the statistical package SPSS $®$ version 20.0 for Windows ${ }^{\circledR}$.

\section{RESUltS}

The collected anthropometric characteristics of the group in the present study showed the values for age $(24.0 \pm 4.5)$ years, body mass $(66.5 \pm 5.4) \mathrm{kg}$, height $(1.76 \pm 0.05) \mathrm{cm}$, BMI $(21.6 \pm 1.6) \mathrm{kg} / \mathrm{m}^{2}$, summation of 7 skin folds $(89.8 \pm 15.2) \%$, fat percentage $(17.2 \pm 2.5) \%$ and body density $(1.059 \pm$ $0.005) \mathrm{g} / \mathrm{cm}^{3}$.

Regarding the perimeter of the body circumferences were obtained Thorax values (81.6 \pm 5.1$)$, Abdomen (80.5 \pm 5.4$)$ Right Arm (28.8 \pm 1.8$)$, Left Arm (28 $3 \pm 1.8)$, Thigh Right (58.5 \pm 3.5$)$, Left Thigh $(58.2 \pm 3.6)$ Right Leg $(35.3 \pm 2.4)$ and Left Leg $(35.3 \pm 2.3)$ where all the results of each test are shown in centimeters.

For skin folds were found the values of axillaries average (7.8 \pm 2.8$)$, sub scapular is $(9.5 \pm 2.2)$, triceps (13.8 \pm 3.1$)$, suprailiac (12.5 \pm 39 9), abdominal (16.2 \pm 4.5$)$, thigh (17.1 \pm 3.9$)$ and leg (12.8 \pm 2.7$)$. The collected results are all expressed in millimeters.

The results of tests performed on Ipanema Beach presented the following data: agility $(6.97 \pm 0.39)$, speed (3.26 \pm 0.22$)$, launched speed $(2.81 \pm 0.25)$ and power $\quad(3.02 \pm 0.37)$. Consequently, the same tests at Barra showed values: agility $(6.91 \pm 0.40)$, speed $(3.30 \pm 0.21)$, launched speed $(2.87 \pm$ $0.35)$ and power $(3.11 \pm 0.40)$, where all results of each test are reported in seconds.

We can see in Table 1, there was no significant statistical difference through the Test "T" test (p $<0.05$ ), with respect to physical tests between Ipanema and Barra Beach. It should be known that even if there were changes in climatic conditions from the beaches, these were not recorded by the researcher. 
Table1. Comparison of the Values Found Physical Tests Between Local

Ipanema and Barra

\begin{tabular}{|c|c|}
\hline Test "T" & $\boldsymbol{p}$ \\
\hline Agility & 0,437 \\
\hline Speed & 0,098 \\
\hline LSpeed & 0,369 \\
\hline Power & 0,203 \\
\hline
\end{tabular}

LaunchedSpeed (L. Speed)

However, after evaluation of the variables with the sample top athletes presented in this research, we suggest as standard references the following data for the speed variable, speed, launched speed and power, according to the description made in our methodology (table 2) all data being expressed in seconds.

Table2. Cut Point Values and Your Rating

\begin{tabular}{|c|c|c|c|c|c|}
\hline \multicolumn{7}{|c|}{ QUARTILES } & Power \\
\hline GREAT & $\mathbf{1}$ & Agility & Speed & 2,31 & 2,38 \\
\hline GOOD & $\mathbf{2}$ & 6,18 & 3,02 & 2,71 & 2,83 \\
\hline REGULAR & $\mathbf{3}$ & 7,09 & 3,15 & 2,82 & 2,87 \\
\hline BAD & $\mathbf{4}$ & 7,19 & 3,22 & 2,95 & 3,39 \\
\hline TERRIBLE & $\mathbf{5}$ & 7,32 & 3,35 & 3,57 & 3,66 \\
\hline
\end{tabular}

LaunchedSpeed (L. Speed)

\section{DisCUSSION}

The literature does not provide any analysis of the physical and functional characteristics of a beach volleyball game. In the study of Schall ${ }^{11}$ with 26 female volleyball athletes presented the following data for the agility test (agility T-Test) coefficient $(0.762)$ and the potency test (vertical jump) the coefficient was (0.932).

In turn, the study Leite et al. ${ }^{12}$ noted that 13 subjects with a mean of $19.46 \pm 2.82$ years of Le Parkour practitioners in which they were evaluated in the vertical jump test (jump squat) with an average of $55.96 \pm 5.31 \mathrm{~cm}$. The results for the practitioners of Le Parkour in this study were higher than the Street Skate practitioners with at least two years of practice; the average value was $46.7 \pm 8.3 \mathrm{~cm}$. This suggests that the practice of Le Parkour develop the power of the lower limbs due to being an acyclic activity like beach volleyball. Levandoski, Cardoso \& Cieslak ${ }^{13}$ observed in their study with 11 indoor volleyball athletes with an average of 15.9 years, the results for the agility test average of 6.59 seconds.

Vieira et al. ${ }^{14}$ evaluated 9 volleyball players and found the average speed for 0.32 seconds and the test power of $0.02 \mathrm{~cm}$.

In their study, Dourado ${ }^{15}$, evaluated 12 male volleyball players intentionally mean of $17.76 \pm 0.71$ years who underwent physical training for seventeen weeks totaling 94.92 hours of preparation and observed for agility test $(30$ meters Buligin, 1981) $(\mathrm{p}=0.000)$ and power test (vertical jump test jump squat) $(\mathrm{p}=0.790)$.

Cabral et al. ${ }^{16}$ in their study, evaluated 40 volleyball athletes performing potency test (vertical jump test - Sergeants adapted Test) resulting for the first group consisting of 21 athletes $43.58 \pm 5.32 \mathrm{~cm}$ and the second group compound 19 athletes $44.47 \pm 3.67 \mathrm{~cm}$. It is observed that the explosive force of lower limbs quantified by the vertical jump height, showed no significant difference between groups.

The study by Santos ${ }^{17}$, can be seen significant correlation between explosive strength measured through the vertical jump test and the travel speed in the 30 -meter test $(r=-0.59$ and $\mathrm{p}<0.05)$. The study Reyes ${ }^{18}$ can be observed that individuals who had higher fat mass had a worse outcome in agility test chosen for each group of football and T-test for volleyball.

According to the study by Silva-Junior et al. ${ }^{19}$ aimed to examine the correlations between sprints powers of 10 and 30 meters and the power vertical jump in young soccer players. The study enrolled 143 male soccer players of under-20 categories $(n=34)$, under-17 $(n=43)$ and under- $15(n=66)$ who 
underwent vertical jump test, 10 speed meters and speed of 30 meters. The results showed low to moderate correlations when comparing the absolute values of time and achieved height $(r=-0.47$ to $0.71)$.

Collaborating with its pilot study, Pellegrinotti and Souza ${ }^{20}$, developed a test called "TW 20m" and its correlation with the test $1000 \mathrm{~m}$ Klissouras (1973) with the objective of evaluating the shifts and jumps, volleyball specific actions. The study authors ware composed of 10 male athletes of children and young people category. The averages of the tests were 198.9 seconds for the linear path and twice traveled to the TW $20 \mathrm{~m}$. The coefficient nonparametric between the paths of $1000 \mathrm{~m}$ and TW $20 \mathrm{~m}$ was (- 0.512), $\mathrm{p}=0.13$. Therefore, the correlation between these two tests was not significant; thereby confirming that the TW $20 \mathrm{~m}$ test is more specific for evaluation of volleyball athlete performance.

Lombardi et al. ${ }^{21}$ observed the comparison of two types of power training types (plyometrics and weight training). Study participants were 16 female athletes of volleyball, which held four weeks of training, 3 times a week. The athletes were divided into three groups, GP (plyometrics), GM (weight) and CG (control). In their findings, a significant increase in vertical jump GM comparing the pre- and post-test ( $p<0.05$ ), which is itself, analyzing the GP groups, GM and GC; there was no statistically significant difference $(\mathrm{p}>0.05)$.

\section{Conclusion}

It is necessary to reiterate that the methodology used here was specially developed for this pilot study. It can be improved in view of the interest of each search that is performed, but that the data contained herein may serve to professionals in practice mode as a reference for future work with similar purposes.

However, some of the contributions included throughout the study cannot be original and innovative, but it is hoped that they can collaborate in a very direct way in improving athletes age group studied, as were presented in a proposal that emphasized some physical valences exercised in volleyball game.

Although one of the goals of this research go through the assessment of athletic performance behavior in physical tests in beach volleyball, the analyzed capabilities, agility, speed, launched speed and power, showed no significant differences. However, it was possible to create a possible profile of the female athlete in the Brazilian beach volleyball, as well as their standard reference values (cutoff values) for agility, speed, launched speed and power.

However it is necessary to conduct similar studies, analyzing athletes of different age groups, as well as a larger number of participants to be appropriate comparisons and in turn, consolidate scientific knowledge on this subject.

Finally, this study is an effort to get more specific information that can contribute in some way to increase knowledge about training, monitoring and the best performance for athletes, specifically in beach volleyball mode, creating proposals for new discussions that may have positive effects in practice.

\section{New Proposals Studies}

For satisfactory results, multidisciplinary work tends to be promising for future research with the same checks carried out in this study, but analyzing more participants, the greater number of trials in each test suggested.

It is also suggested that in future studies employ objective and detailed measures of performance athletes, in addition to specific ranges of sports area, so they can be established the type and degree of correlation between the speed variable, speed and power in different situations.

\section{REFERENCES}

[1] Pitanga, F. J. G. (2001). Testes, medidas e avaliação em educação física e esportes. 2.ed. Salvador: Edição do autor.

[2] Gilmário, R. B. Comparação antropométrica, composição corporal, somatotipo e saltos verticais de atletas de voleibol de praia masculino. (2008). Tese de doutorado Universidade Federal do Rio grande do Norte.

[3] Barbanti, V. J. Treinamento físico: bases científicas. (1986). São Paulo: CLR Balieiro. 
[4] Tubino, M. J. G. \& Moreira S. B. Metodologia científica do treinamento desportivo. (2003). Rio de Janeiro: Shape.

[5] Arruda, M., \& Hespanhol, J. E. Fisiologia do voleibol. (2008). São Paulo: Phorte.

[6] Carvalho, C. \& Carvalho, A. Não se deve identificar força explosiva com potência muscular, ainda que existam algumas relações entre ambas.Rev. Port. Cien. Desp. (2006). v. 6, n. 2, p. 241248.

[7] Kraemer, W. J. \& Hakkinem, K. Strength training for sport. Blackwell Science. (2002). Iowa: USA.

[8] Ré, A. H. N. et. al. Relações entre crescimento, desempenho motor, maturação biológica e idade cronológica em jovens do sexo masculino. Revista Brasileira de Educação Física e Esporte, São Paulo. (2005). v. 19, n. 2, p. 153-62.

[9] ISAK. International Standards for Anthropometric Assement. (2001). Australia.

[10] Jackson, A. S., Pollock, M. L. Generalized equations for predicting body density of men. British Journal of Nutrition. (1978). v. 40, p. 497-504.

[11] Schall, M. L. Physiologic performance test differences by competition level and player position in female volleyball athletes. Thesis for the degree of Master of Science in Exercise and Sport Studies, Biophysical Studies Boise State University. (2011).

[12] Leite, N. et. al. Perfil da Aptidão Física dos Praticantes de Le Parkour. Rev Bras Med Esporte. (2011). v. 17, n. 3, p. 198-201.

[13] Levandoski, G., Cardoso, F. L., Cieslak, F. Perfil somatótipo, variáveis antropométricas, aptidão física e desempenho motor de atletas juvenis de voleibol feminino da cidade de Ponta Grossa / PR. Fit Perf J. (2007). v. 6, n. 5, p. 309-14.

[14] Vieira, N. A. et. al. (2008). Efeito do treinamento de resistência de força no sistema neuromuscular em atletas de voleibol. Revista Conexões, Campinas, v. 6, p. 83-95.

[15] Dourado, A. C. Monitoração de adaptações antropométricas, motoras e modelação estrutura do desempenho esportivo de atletas de voleibol durante período de preparação. (2007). Tese de doutorado, Universidade do Rio grande do Sul.

[16] Cabral, B. G. A. T. et al. Efeito discriminante da morfologia e alcance de ataque no nível de desempenho em voleibolistas. Rev Bras Cineantropom Desempenho Hum. (2011). v. 13, n. 3, p. 223-229.

[17] Vieira, N. A. et. al. Efeito do treinamento de resistência de força no sistema neuromuscular em atletas de voleibol. Revista Conexões, Campinas. (2008). v. 6, p. 83-95.

[18] Reyes, Y. G. Validez, fiabilidad y especificidad de las pruebas de agilidad. Revista U.D.C.A Actualidad \&Divulgación Científica. (2008). v. 11, n. 2, p. 31-39.

[19] Silva-Junior, C. J. et. al. Relação entre as potências de sprint e salto vertical em jovens atletas de futebol. Motricidade. (2011). v. 7, n. 4, p. 5-13.

[20] Pellegrinotti, I. L., Souza, S. J. G. Criação do teste W 20 metros para predição do V02máx em indivíduos de ambos os sexos atletas de voleibol. Revista Treinamento desportivo. (2003). p. 1628. São Paulo.

[21] Lombardi, G., Vieira, N. S., Detanico, D. Efeito de dois tipos de treinamento de potência no desempenho do salto vertical em atletas de voleibol. Brazilian Journal of Biomotricity. (2011). v. 5, n. 4 , p. $230-238$. 